\title{
Vesicoscopy Technique and Applications in Children: Our Experience
}

\section{Antonio Marte*}

Pediatric Surgery, Second University of Naples, Italy

\begin{abstract}
Aims: The aim of this study is to describe vesicoscopic technique in the treatment of congenital bladder diverticula and vesicoureteral reflux (VUR) in children.

Patients: With the vesicoscopic technique, 58 patients havebeen treated at our Institution from January 2007 to January 2013. There were 13 pts with congenital bladder diverticula and 45 pts with persistent grade $\geq 3$ VUR. Under cystoscopic control, three trocars were placed (one at bladder dome, two laterally). The reimplantation was implemented using Cohen's technique. In case of megaureter, the ureter was brought out the bladder and tailored. The diverticula were inserted into the bladder progressively and then removed.
\end{abstract}

Results: Operating time ranged from 50 to 240 minutes. Three patients developed mild suprapubic emphysema after surgery. No patient was converted to open surgery or needed additional trocars. Renal scan with MAG3, VCUG and ultrasound performed in all patients 3 to 6 months after surgery showed the resolution of reflux in 31 out of 33 patients: an asymptomatic monolateral $1^{\text {st }}$ grade reflux persisted in one girl who had been treated for monolateral $4^{\text {th }}$ grade reflux, and in one boy with refluxing megaureter. All patients with diverticula presented full resolution.

Conclusion: Our experience seems to show that the vesicoscopic treatment of bladder diverticula, vesicoureteral reflux and megaureter is safe andeffective and can represents a new viable alternative to the traditional procedures.

Keywords: Vesicoscopy; Children; VUR; Bladder diverticula

\section{Introduction}

Vesicoscopic surgery is a recent technique utilized in children mainly to correct vesicoureteral reflux (RVU) and the removal of Bladder Diverticula (BD). The first experiences reported by some Authors are very encouraging, transferring the aptness acquired with laparoscopy to this specific organ [1-3]. The surgeon works in the bladder through three ports inserted suprapubically, usually three $5 \mathrm{~mm}$ for the camera and two $3-5 \mathrm{~mm}$ working ports. The trocars are introduced under direct vision by cystoscopyand the bladder is filled with $\mathrm{CO}_{2}$ expelling the filling water. The only drawback can be the reduced working space-especially in smaller children-and the difficulty in knotting.

The main advantages, on the other hand, are a reduced trauma to the organ, less clots, less bladder spasm, a rapid recovery, with results similar to open bladder surgery.

Megaureters can also be easily treated, bringing them out the bladder through the urethra or the trocar hole and then reintroduced into the bladder and reimplanted [4].

We report here on the use of vesicoscopic surgery in the treatment of congenital bladder diverticula and vesicoureteral reflux.

\section{Patients}

With this technique, 58 patients were treated at our Institution from January 2007 to January 2013. They were:- 45 patients, 32 females, 13 males, aged 3 to 7 yrs, mean age 4.5 yrs, with VUR $3^{\text {rd }}$ to $5^{\text {th }}$ Grade, 29 monolateral VUR, 16 bilateral VUR. Patients (13) males, aged 4-12 yrs, mean age 6.2 yrs, with 3 double, 10 single diverticula. Location: postero-lateral bladder wall.

All patients with VUR presented recurrent urinary tract infection refractory to antibiotic prophylaxis and/or renal scars and 21 had experienced antibiotic treatment for 1 or more years, 12 had also undergone1 or 2 unsuccessful endoscopic treatments. All patients were monitored with Ultrasound Scan (US), cystourethrograms (VCUG) and DMSA scan. No patient with VUR/megaureter presented dysfunctional voiding at the operation. Of the patients with $\mathrm{BD}$, three 9 presented voiding disorders and overactive bladder at urodynamics associated to recurrent urinary infection, four with gross hematuria and urinary tract infection.

\section{Surgical Technique}

\section{Vesicoureteral reflux}

The procedure followed the following steps: the patients were placed in the lithotomy position with abducted thighs and the pelvis tiltedwith a cushion placed below the buttocks. Standard cystoscopy recognition was performed to verify the condition of the urethra and the ureteric orifices. A $3 \mathrm{CH}$ ureteral sund was introduced in both the ureters. The bladder was then filled at its maximum capacity, and a first $5 \mathrm{~mm}$ trocar was introduced for a $0^{\circ} \backslash 30^{\circ}$ telescope at the bladder dome; two lateral 3 or $5 \mathrm{~mm}$ trocars were then inserted under visual control into the bladder at level of midclavicular line. With the use of $3 \mathrm{~mm}$ trocars, with the bladder filled, the bladder wall was suspended to the anterior abdominal wallby two percutaneous transfixing sutures (no.1 or no.2 polyglactin stitches) placed under cystoscopic control. This allowed keeping the bladder wall close to the abdominal wall, in order to stabilize the bladder and facilitate the introduction of the trocars. When using the $5 \mathrm{~mm}$ locking trocars cystopexy was avoided. A urethral catheter wasthen left in place removing the cystoscope and the bladder was filled with $\mathrm{CO}_{2}$ at a pressure of 10-12 $\mathrm{mmHg} \mathrm{cm}_{2} \mathrm{O}$ and a volume of $2 \mathrm{~L} /$ minvia the dome port. To perform the reimplantation we utilized a 3 or a $5 \mathrm{~mm}$ needle holder, a grasper, a pair of scissors, a

*Corresponding author: Antonio Marte, Pediatric Surgery, Second University of Naples, Largo Madonna delle Grazie, 80138 Naples, Italy, Tel: 0823274128, +39 0823329 988; E-mail: antonio.marte@unina2.it

Received October 05, 2013; Accepted February 07, 2014; Published February 14,2014

Citation: Marte A (2014) Vesicoscopy Technique and Applications in Children: Our Experience. Surgery Curr Res 4: 176. doi:10.4172/2161-1076.1000176

Copyright: (c) 2014 Marte A. This is an open-access article distributed under the terms of the Creative Commons Attribution License, which permits unrestricted use, distribution, and reproduction in any medium, provided the original author and source are credited. 
monopolar hook and a peanut. The ureteral orifice(s) was fastened to the probe by means of a transfixed stitch and then attracted into the bladder (Figures 1-3).

The bladder mucosa around the orifice was incised by scissors and hook and the ureter was then freed obtaining a sharp plane between the detrusor muscle and the ureteral wall. To work in a limited working space, the "spaghetti technique", rolling the ureter around the needle holder or the grasper [5,6], made easier the ureteral isolation. In case of megaureter, the ureter was brought out the bladder and tailored, as proposed by Valla [4], outside the bladder, through the urethra in girls or through the hole of the ipsilateral lateral port in boys. The sub mucosal tunnel(s) was then set up with the scissors and the graspers by lifting the bladder mucosa and through a combination of blunt and sharp dissection. The detrusor below the ureter wasrepaired with one or two absorbable stitches toavoid diverticula and prevent retroperitoneal gas leakage. The optical magnification and the positive pressure resulted very useful to identify the dissection plane. The ureter was then passed through the tunnel without removing the dissected distal portion which was utilized for the traction and removed only after the first stitch of the Cohen's reimplantation. An additional three-four

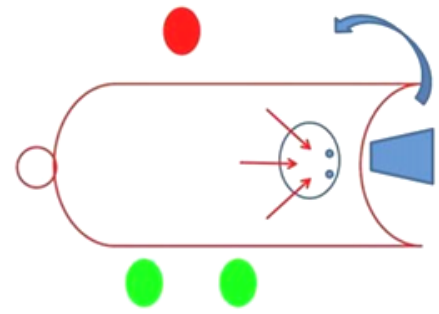

Figure 1: Vesicoscopy set up: Patient is placed in dorsal lithotomy position with the surgeon standing to the patient's right looking at a monitor between the legs or over the left leg.

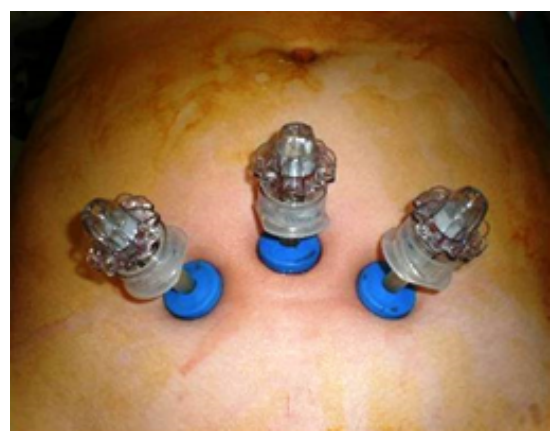

Figure 2: Operative view of vesicoscopy. Three self -blocking trocars has been utilized (no cystopexy needed).

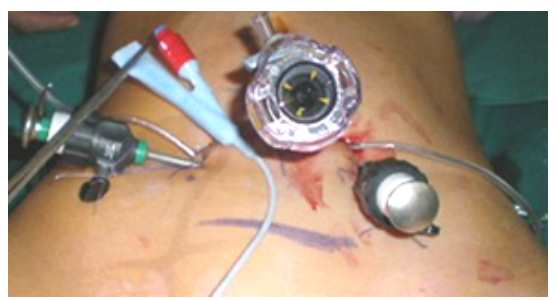

Figure 3: Operative view of vesicoscopy. Three standard 3 and $5 \mathrm{~mm}$ trocars have been utilized. In this case 2 stitches of cystopexy are necessary to fix the bladder to the abdominal wall.
5-6/0 maxon sutures were applied to create the anastomosis. When a locking trocar ( $5 \mathrm{~mm}$ instrument-channel) was used, the attraction of the ureter beneath the submucosal tunnel was facilitated by the use of a $5 \mathrm{~mm}$ roticulator. After grabbing the end of the ureter, the roticulator was utilized to obtain an easy and straight traction. Another useful tool is to reduce the $\mathrm{Co}_{2}$ pressure to $5-6 \mathrm{mmHg}$ during the dissection in order to obtain a greater angulation of the instruments. The fact that some patients had previously undergone endoscopic single or multiple dextranomer/hyaluronic acid injections did not represent a problem. At the end of the procedure, in some cases a ureteral double J stent was left in place for 3 to 4 weeks if the dilated ureter needed a long tailoring. Before removing the trocars the bladder was irrigated and checked for bleeding. The sites of the $5 \mathrm{~mm}$ lateral ports were sutured with $3 / 0$ polyglactin stitches passed with a Reverdin needle. The urethral and suprapubic catheters were removed 3-4 days after the procedure. A 12Ch Foley catheter filled with 3-4 $\mathrm{ml}$ sterile water can be also introduced at the site of the $5 \mathrm{~mm}$ dome-port through the trocar or with the help of a guide-wire if a suprapubic derivation is deemed necessary [1]. The two sites of the $3 \mathrm{~mm}$ trocars did not require closure. Postoperative follow-up consisted of clinical examination, renal ultrasound and retrograde cystography (medium follow-up 28 months) (Figures 4 and 5).

\section{Bladder diverticula}

The procedure followed the same initial and final steps of VUR treatment. The procedure required only $3 \mathrm{~mm}$ instruments, needle holder, grasper, scissors and a monopolar hook. The smallest diverticula were inverted and removed using the hook and the scissors. The bigger ones instead were gradually inverted into the bladder and the mucosa around the neck was incised and freed by creating a plane between the detrusor and the mucous membrane. When the dissection was completed, the closure of the wall was performed by a double or a single layer of interrupted polyglactin absorbable sutures, passed through the trocarsor through the abdominal wall (Figures 5 and 6). The diverticulum was then removed under visual control, either entirely or divided into smaller pieces. In this way also the largest diverticula can be successfully resected. A foley catheter was left in place for one to three days (Figure 6).

\section{Results}

Regarding the patients treated for VUR, operating time ranged from 80 to 240 minutes. Three patients, developed mild suprapubic emphysema after surgery, which reduced the working space thus lengthening the operative time. No major perioperative or postoperative complications were recorded. No patient was converted to open surgery or required additional trocars. Blood loss was very minimal in all cases. After a mean follow-up of 12 months all the patients are doing well and free of symptoms. All patients were kept on oral antibiotic prophylaxis for three months.

Renal scan with MAG3, VCUG and ultrasound performed in all patients 3 to 6 months after surgery showed the disappearance of reflux in 31 out of 33 patients: one girl who had been treated for monolateral $4^{\text {th }}$ grade reflux, and one boy with refluxing megaureter. Three patients presented a transient, asymptomatic ureteral dilatation observed at follow-up ultrasound. In patients with VUR recurrence, the reflux was resolved by continuing antibiotic-prophilaxis in the boy, while the girl underwent successful endoscopic treatment with Deflux.

Patients with diverticula presented full resolution in all cases confirmed by VCUG and urodynamics. Mean operative time 


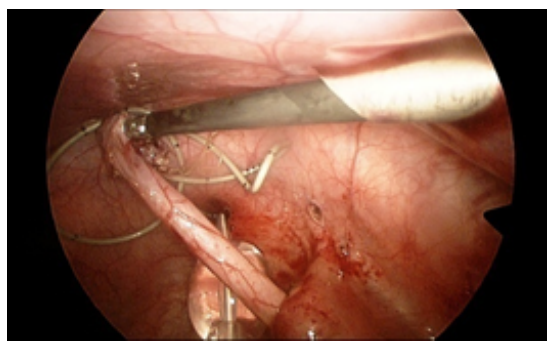

Figure 4a: Isolation of the ureter with the help of "spaghetti technique" (the ureter is rolled around the grasper during the isolation).

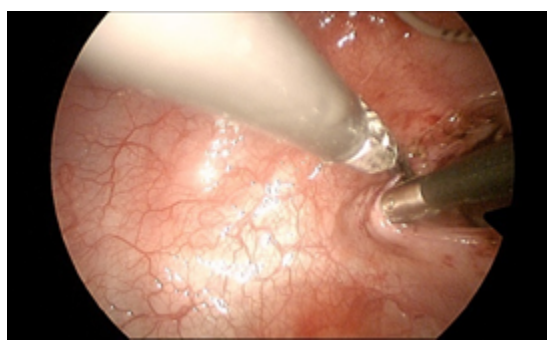

Figure 4b: Dissection of the submucosal tunnel.

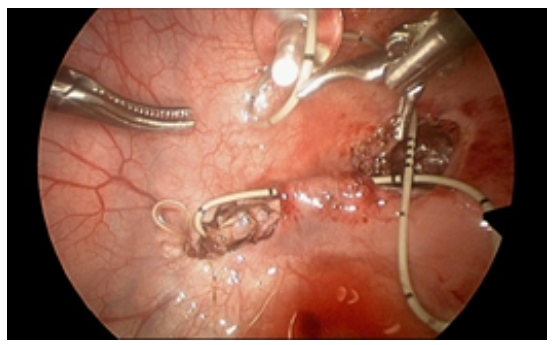

Figure 4c: Cohen's reimplantation.

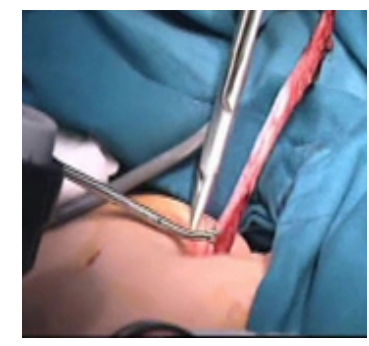

a Extravesical transurethral tailoring of the ureter

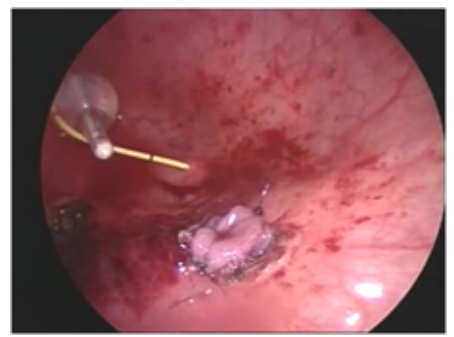

b Final view of Chen's reimplantation
Figure 5: Vesicoscopic treatment of refluxing megaureter.

ranged from 50 to 140 minute (mean 90 minutes). No major peri or postoperative complications were recorded in these patients. The only drawback was represented by the displacement of a lateral $3 \mathrm{~mm}$ trocar outside the bladder, resulting in gas leakage in the extravesical space in 8 -year-old patient with double diverticula. In this case, the trocar needs to be replaced, thus prolonging operating time.

US and VCUG were performed 6 months after the operation and showed the disappearance of the diverticulum/a. Patients with voiding disorders presented a gradual improvement of their urgency, which was also confirmed by the urodynamics.

\section{Discussion}

Our experience has shown that the vesicoscopy is a minimally invasive, reliable, safe and effective technique.

While it appears that vesicoscopic diverticulectomy, thanks to its mini-invasiveness, relative ease and safety, can be considered the gold standard, the trans vesicoscopic reimplantation remains a difficult procedure; this is especially true when treating children with megaureter, given the greater number of maneuvers and numerous sutures to be performed in a reduced working space, which require a skilled laparoscopic surgeon [7].

Recently vesicoscopic surgery has become part of urological procedures in pediatric age, at least in some institutions. In the meantime some Authors have proposed other indications for vesicoscopy, such as bladder neck injection or bladder neck plasty for the treatment of urinary incontinence [8]. Recently some Authors have proposed also with good results the vesicoscopic Politano - Leadbatter procedure.

The first experiences reported [1,2] described the use of vesicoscopy in children for the treatment of vesicoureteral reflux and obstructive megaureter. The Authors concluded that cross-trigonal ureteral reimplantation could be performed safely and effectively, with a success rate in reflux resolution as high as with the open technique, but with minimal invasiveness and much faster recovery [2]. Moreover, other Authors underline the need for the surgeon of a long learning curve for performing this procedure, and, given the limited working space, the need for great caution when considering its use in young patients with small bladder capacity [9]. This procedure has also been performed using robotics, as shown by the good results achieved by Peters [10]. Valla, in a recent study on seventy-two patients (mean age 4.2 years, range $0.5-20$ years) with primary reflux, reported a $92 \%$ success rate on 113 ureters reimplanted. Four cases (6\%) required conversion to open surgery, and reflux persisted in another four (8\%). In this studywhich is probably, at present, the largest single-center experience - the Author reports that conversion was necessary in patients aged less than 2 years, probably due to greater mobility of the bladder [11]. According to Kutikov et al. [9], a cystographic bladder capacity of $130 \mathrm{cc}$ could today be considered the limit for vesicoscopic ureteral reimplantation.

Therefore although in our experience we have not had to convert to open surgery (no patient aged below 3 years), we think that this possibility should be always considered when asking for informed consent. One of the drawbacks of vesicoscopy is the need to place suture stitches in the small space available in the bladder cavity, which requires sufficient expertise. On the other hand, the vesicoscopy allows the surgeon to perform an operation very similar to the open technique, along with all the advantages of mini-invasive access.

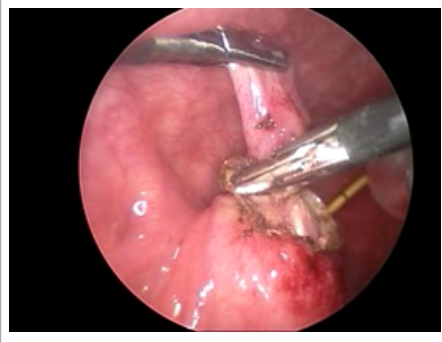

a. Intraoperative view of the inverted diverticulum

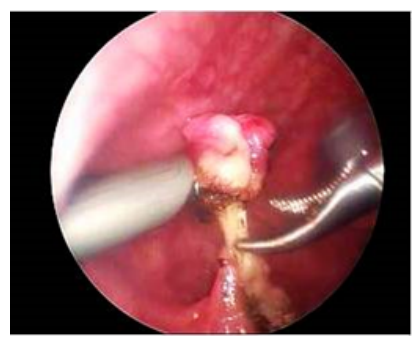

b.Diverticulum resection
Figure 6: Vesicoscopic diverticulectomy. 
The advantages of the vesicoscopic surgery are also the reduction of abdominal and bladder trauma: in fact, there is no cystotomy, no stretching of the detrusor muscle and no mucosal irritation due to the gauze swabs. Another advantage may be also the reduction of postoperative hematuria or clots formation and bladder spasm due to the large detrusor opening. In our opinion, the routine utilization of vesicoscopy could become the gold standard for the treatment of all intravesical procedures, keeping at the same time the advantages of the open technique.

Regarding the vesicoscopic diverticulectomy, in our experience this technique resulted very effective and safe with fast recovery and short hospital stay. Moreover direct diverticulectomy with this miniinvasive access could also enable the surgeon to correct other associated pathologies, such as VUR. Other mini invasive effective technique have been also utilized for performing diverticulectomy as we the standard or laparoscopic robotic-assisted diverticulectomy $[12,13]$. Nevertheless, the violation of the peritoneum should be considered one of the major drawbacks of this approach [12].

\section{Conclusion}

In our experience, vesicoscopy in the treatment of bladder diverticula and vesicoureteral reflux is an effective and safe procedure and can be considered a viable alternative to open or laparoscopic procedure. This technique implies also a quick and painless postoperative course and good aesthetic results.

This experience has also shown that endoscopic intravesical ureteral mobilization and cross-trigonal ureteral reimplantation can be performed safely and effectively with standard laparoscopic pediatric instruments, under $\mathrm{CO}_{2}$ insufflation of the bladder, achieving a high success rate in reflux resolution, equivalent to that obtained with the open technique. Furthermore the optical magnification allows the surgeon to perform precise and fine movements both during dissection that during reimplantation. Vesicoscopy provides also a rapid recovery, no postoperative discomfort and good cosmetic results.

This minimally invasive approach should be considered as a viable alternative to open surgery or to repeated unsuccessful endoscopic injection for the treatment of VUR.

The longer-term outcome and potential physiological effects of $\mathrm{CO}_{2}$ pneumovesicum on the bladder and upper-tract function will need further evaluation even if some preliminary report is encouraging [14]. Moreover the number of patients evaluated in this study is still small to allow definitive conclusions to be drawn.

\section{References}

1. Yeung CK, Borzi PA (2002) Pneumovesicoscopic Cohen uretericreimplantation with carbon dioxide bladder insufflation forgross VUR. Br J Urollnt 89: 15-86.

2. Yeung CK, Sihoe JD, Borzi PA (2005) Endoscopic cross-trigonal uretera reimplantation under carbon dioxide bladder insufflation: a novel technique. $\mathrm{J}$ Endourol 19: 295-299.

3. Badawy H, Eid A, Hassouna M, Elkarim AA, Elsalmy S (2008) Pneumovesicoscopic diverticulectomy in children and adolescents: is open surgery still indicated? J Pediatr Urol 4: 146-149.

4. Valla JS (2007) Transvesicoscopic Cohen ureteric reimplantation for vesicoureteral reflux in children. In: Godbole PP (ed.) Pediatric EndourologyTechniques. Springer-Verlag: London 39-46.

5. Durai R, Ng PC (2009) "Spaghetti technique"-novel technique to facilitate laparoscopic appendicectomy and cholecystectomy. J Laparoendosc Adv Surg Tech A 19: 667-668.

6. Marte A, Cavaiuolo S, Pintozzi L, Prezioso M, Nino F, et al. (2011) "Spaghetti maneuver": a useful tool in pediatric laparoscopy - our experience. Afr J Paediatr Surg 8: 252-255.

7. Marte A, Sabatino MD, Borrelli M, Nino F, Prezioso M, et al. (2010) Pneumovesicoscopic correction of primary vesicoureteral reflux (VUR) in children. Our experience. Eur J Pediatr Surg 20: 366-370.

8. Lee DH, Oh CY, Jang HS, Hong CH (2013) Bladder neck injection of a polydimethylsiloxane-bulking agent under pneumovesicum for treatment of children with urinary incontinence: report of 3 cases. J Laparoendosc Adv Surg Tech A 23: 297-300.

9. Kutikov A, Guzzo TJ, Canter DJ, Casale P (2006) Initial experience with laparoscopic transvesical ureteral reimplantation at the Children's Hospital of Philadelphia. J Urol 176: 2222-2225.

10. Peters CA, Woo R (2005) Intravesical robotically assisted bilateral ureteral reimplantation. J Endourol 19: 618-621.

11. Valla JS, Steyaert H, Griffin SJ, Lauron J, Fragoso AC, et al. (2009) Transvesicoscopic Cohen ureteric reimplantation for vesicoureteral reflux in children: a single-centre 5-year experience. J Pediatr Urol 5: 466-471.

12. Jarrett TW, Pardalidis NP, Sweetser P, Badlani GH, Smith AD (1995) Laparoscopic transperitoneal bladder diverticulectomy: surgical technique. J Laparoendosc Surg 5: 105-111.

13. Fukatsu A, Okamura K, Nishimura T, Ono Y, Ohshima S (2001) [Laparoscopic extraperitoneal bladder diverticulectomy: an initial case report]. Nihon Hinyokika Gakkai Zasshi 92: 636-639.

14. Xiang B, Liu JX, Sung HB, Yan B, Cheng W (2010) The effect of CO2 pneumovesicum on upper urinary tract. J Pediatr Surg 45: 1863-1867. 